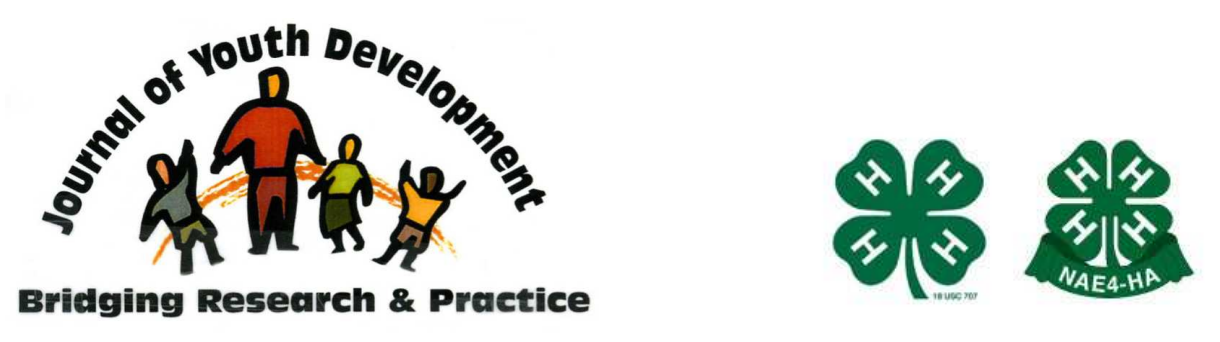

\title{
Planting the Seed: An Evaluation of a Community Youth Summit
}

\author{
Corliss Outley \\ Child \& Adolescent Health Research Lab \\ Department of Recreation, Park \& Tourism Sciences \\ Texas A\&M University \\ College Station, TX \\ coutley@ag.tamu.edu \\ E. Lisako J. McKyer \\ Child \& Adolescent Health Research Lab \\ Department of Health \& Kinesiology \\ Texas A\&M University \\ College Station, TX \\ Matthew Lee Smith \\ Child \& Adolescent Health Research Lab \\ School of Rural Public Health \\ Texas A\&M University \\ College Station, TX
}




\title{
JOURNAL OF YOUTH DEVELOPMENT \\ bridging research and practice

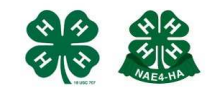

Volume 05, Number 03, Fall 2010

Article 100503PA002

\section{Planting the Seed: An Evaluation of a Community Youth Summit}

\author{
Corliss Outley, E. Lisako J. McKyer and Matthew Lee Smith \\ Texas A\&M University
}

\begin{abstract}
Meaningful youth engagement produces benefits both to youth and to the community in which they live. This paper discusses a day-long youth summit held for 289 middle school students. Youth attended a combination of mass and break-out sessions based on America's Promise Five Promises. Planners and evaluators assessed proximal student outcomes throughout the day. A two question visual analog scale was developed and utilized to assess students' perceptions of learning and enjoyment.
\end{abstract}

\section{Introduction}

The community youth development (CYD) framework promotes youth engagement opportunities as a viable avenue for positive youth and community development. CYD includes positive youth development (Lerner, 2003), while also emphasizing youth-adult partnerships to create social change (Camino \& Zeldin, 2002). Perkins and Borden (2003) define CYD as "purposely creating environments that provide constructive, affirmative, and encouraging relationships that are sustained over time with adults and peers, while concurrently providing an array of opportunities that enable youth to build their competencies and become engaged as partners in their own development as well as the development of their communities"(p.6). Providing youth with opportunities to engage in the community allows youth to acquire lifelong learning skills that assist in their development. Furthermore, youth community engagement contributes to community development by focusing on solutions to assist local issues facing their community (Perkins, Borden, Keith, Hoope-Rooney, \& Villarruel, 2003). By placing an emphasis on the role youth can take within a community, we can begin to view youth not as passive actors but individuals that have a voice and can share in the decision-making process that affects their lives and the community they reside in.

\section{America's Promise}

The five "Promises" articulated by the America's Promise Alliance (1997) provide a framework rooted in community youth development philosophy. The Five Promises are research-based, 
developmental needs that children and youth require from birth into the transition to adulthood. These promises include: Caring Adults, Safe Places and Constructive Use of Time, A Healthy Start and Healthy Development, Effective Education for Marketable Skills and Lifelong Learning, and Opportunities to Make a Difference through Helping Others. These promises are designed as indicators to learn about the inputs, experiences, and opportunities that young people can experience to avoid problem behaviors and also thrive developmentally. In order to describe the well being of children and youth, a holistic picture is needed of their community and the developmental resources it possesses to assist in caring for and preparing them for the future.

Bryan/College Station was named a Community of Promise by the national America's Promise organization in June 2005. The designation was initiated by the Service-Learning Youth Action Board of Bryan High School in the fall of 2000 after returning from the National Youth Summit conference. The students challenged the City of Bryan to apply for the Community of Promise title by making numerous presentations to various agencies and organizations and assisted in the application process. As a Community of Promise, the cities of Bryan and College Station, Texas developed a Board that focuses on the development of character and competence in a child's life and believes that success is dependent on the Five Promises being fulfilled. The Board consists of representatives from local non-profit organizations and agencies (i.e. United Way and local food bank), public entities (i.e. City of Bryan, College Station Independent School District, and Texas A\&M University), private companies (i.e. Atmos Energy) and local youth. During the Fall of 2008 the Bryan/College Station Community of Promise Board organized a community based youth summit that incorporated many of the principles of community youth development and encouraged the engagement of adults, youth leaders and their peers.

\section{Youth Summits}

Youth that participate in community development efforts are shown to receive many benefits (Breitbart \& Kepes, 2007; Cahill, 2007; Checkoway, Dobbie, \& Richards-Schuster, 2003; Goodyear \& Checkoway, 2003). Organized youth activities have been shown to be popular and effective in delivering content and providing experiences associated with positive youth development. Hansen, Larson \& Dworkin's (2003) study results indicate that organized youth activities that provide quality content and positive experiences are not only popular among youth but also provide many developmental assets. Non-profits, volunteer organizations, and governmental programs that work with or on behalf of youth have begun to emphasize the role and impact of youth in community development efforts by focusing on the delivery of these developmental assets via community wide youth summits. By focusing on engaging youth with activities that stimulate enthusiasm and investments in community structures and policy, youth summits have promoted active collaboration between youth leaders, community professionals, volunteers, and youth to identify community issues (i.e., life skills, fiscal responsibility and health) deemed necessary for future civic participation. This paper describes the Bryan/College Station Youth Summit and the assessment of the participants' perceptions about how much they learned and their level of enjoyment during each session.

\section{Methods}

The Bryan/College Station 2008 Youth Summit (BCS Youth Summit) was based on the principles of America's Promise Alliance (1997), and aimed to deliver the Alliance's "five promises" to targeted disadvantaged youth. The Alliance's research-based framework for youth development focuses on every child having:

1) Caring Adults, 

2) Safe Places,
3) A Healthy Start,
4) Effective Education, and
5) Opportunities to Help Others.

The 2008 BCS Youth Summit included five sessions based on the aforementioned promises (i.e., one mass session and four break-out sessions). The summit was planned by the Bryan/College Station Community of Promise Board. Each session lasted between 30 minutes to one hour with ten minutes allowed to transition between sessions. Sessions were held in different rooms throughout the summit's venue. Sessions integrated lecture, discussion, and activities to elicit participant engagement and allow them to apply the content and concepts presented. Each of the summit sessions is described below:

- Ready for 21. The purpose of this session was to introduce participants to caring adults working in professions of interest to youth. Utilizing a pre-administered questionnaire used to determine the vocational interests of participants-to-be, BCS Youth Summit coordinators were able to group participants with caring adults in distinct professional fields for structured interaction. The Caring Adults discussed their job responsibilities and day-to-day work activities with summit participants. Participants were then able and encouraged to pose questions to stimulate conversation and clarify inquiries regarding career development.

- Healthy Start. The purpose of this session was to teach participants the importance of nutrition and teach participants how to make quick, healthy, and low-cost snacks. The facilitator of this session incorporated youth participants into the presentation by allowing them to demonstrate the procedures of making healthy trail-mix and yogurt smoothies. During this session, participants were provided a snack while learning the benefits of low-fat diets, consuming recommended portion sizes, and eating a balanced variety of foods.

- Job Skills. The purpose of this session was to introduce effective life long learning skills to participants by focusing on the concept of personal finances and techniques to manage his/her money. The facilitator of this session used a combination of lecture and discussion to ensure comprehension of session content. Additionally, a board game was played to allow participants an opportunity to apply the knowledge and skills learned during lecture.

- Safe Places. The purpose of this session was to teach participants the importance of internet safety and lifelong learning skills to identify internet threats and avoid internet predators. Facilitators of these sessions utilized uniform PowerPoint presentations to inform participants about proper Facebook etiquette and constructing responsible and safe Facebook profiles. Participants were presented with fictitious Facebook profile examples and then led, through discussions by facilitators, to identify inappropriate content in Facebook profiles and why the inclusion of such content may be potentially harmful.

- The Call. The final session introduced the concept of service learning and community engagement to the participants and provides an avenue for opportunities to help others. The local United Way Youth Council served as coordinators and mentors for a city wide service learning event which all participants would participate in. The youth council introduced the event by conducting a skit to illustrate the role of service in the community and introduced various avenues for participant involvement. This was the 
only session that utilized peer-to-peer instruction to demonstrate leadership development and youth voice.

\section{Target Population}

This study involved a purposive sample (Creswell, 2003) of 289 participants. Participants were identified as eligible to attend the BCS Youth Summit by their middle school teachers. Teachers were provided a checklist using objective criteria to identify disadvantaged students. Based upon teachers' selections, students' parents were sent recruitment letters and consent forms to enroll their child in the summit. Active parental consent was required for students to attend the event. A total of $2896^{\text {th }}, 7^{\text {th }}$, and $8^{\text {th }}$ grade participants from 4 local middle schools attended the BCS Youth Summit.

\section{Measures}

Youth summit planners recognized the need for collecting evaluation data beyond merely tallying the number of participants who attended the event. Of equal or greater importance was the need to collect

(1) information to assist in the improvement of subsequent summits,

(2) data to document goal achievement; and

(3) evidence which may be parlayed into securing additional event sponsorship, support, and funding in future years.

A Brief Visual Analog Survey Measure for Youth (VAS) instrument was developed and utilized to assess participants' perceptions following each of the four youth summit break-out sessions. The instrument consisted of two questions: (1) How much did I learn this session? and (2) How much did I enjoy this session? Response options were on a 3-point Likert-type scale and enhanced by a visual analog to facilitate comprehension by children with wide-ranging reading abilities (see Figure 1).

Participants' perceptions of the BCS Youth Summit were measured using:

(1) The Visual Analog Survey Measure for Youth (VAS) (McKyer, Outley and Smith, 2009) was utilized to assess participants' perceptions at the BCS Youth Summit. The instrument contained two 3-point Likert-type rating scale items that asks participants to indicate their level of learning and the extent of their enjoyment for each session attended. Items were scored using a visual analog to facilitate reading comprehension regardless of ability (see Figure 1$)$. The reliability $(a=0.83)$ of the measurement was deemed acceptable.

(2) Evaluator Observations of participants during each session. Each evaluator was trained to observe participant and session facilitator interactions. Verbal expressions and visual emotions were reported. Specific expressions regarding enjoyment and engagement were emphasized as well. 


\section{Figure1. Brief Visual Analog Measure for Youth}

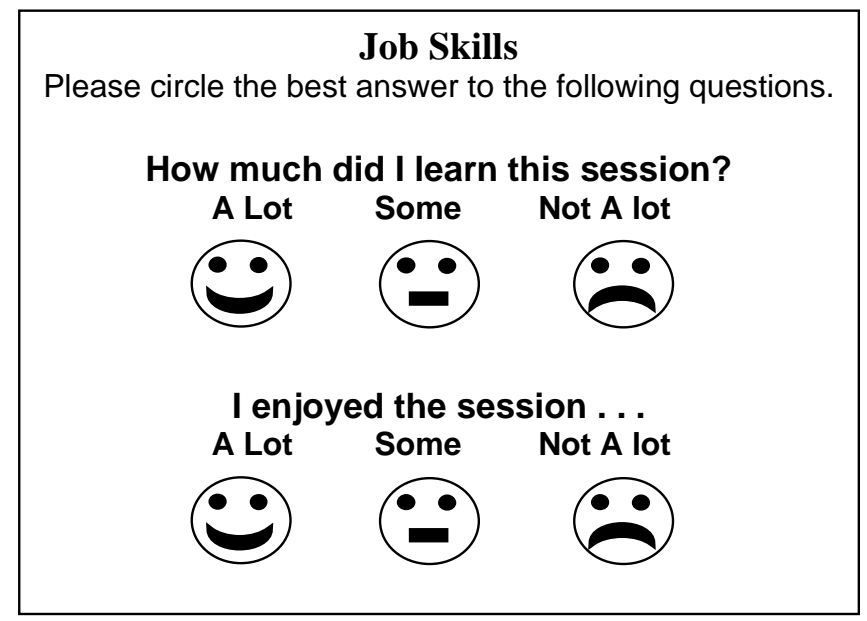

\section{Protocol}

Summit adult and youth volunteers were given an orientation that covered the summit goals, local logistics, and the evaluation protocol (i.e., dissemination times, locations and collection procedures). Each summit participant was provided an evaluation once they entered a selected session. This allowed the authors to have an accurate count of the number of surveys distributed. At the end of each session, a volunteer provided a reminder that participants should complete an evaluation and submit upon exiting the room by dropping into a colored bag (that matched the survey color) at a collection station located at the exit doors. Once all session surveys were collected, the collection bags were sealed and labeled (see Table 1). Completion rates for each session were calculated by comparing the number of surveys distributed with the number collected.

\section{Table 1}

\section{Youth Summit Session Logistics}

\begin{tabular}{|lcccc|}
\hline & Ready for 21 & Safe Places & Healthy Start & Job Skills \\
\hline \hline Number of Rotations & 1 & 3 & 3 & 3 \\
Number of Classrooms & 1 & 6 & 1 & 2 \\
Total Sessions & 1 & 18 & 3 & 6 \\
Number of Room Exits Per Room & 3 & 1 & 1 & 1 \\
\hline & 3 & 18 & 3 & 6 \\
\hline Total Number of Bags Needed & & Blue & Green & Yellow \\
\hline Paper \& Bag Color & White & Blen
\end{tabular}

* For Dual-wide doors, may want to have a bag on each side of the door. Thereby double the number of bags per door.

\section{Results}

The majority of the 289 BCS summit participants completed the evaluation surveys. The Ready for 21 sessions had the highest completion rate of $93.43 \%$ and the Safe Places session had the lowest (73.01\%) (See Table 2). 
Table 2

Youth Summit Session Evaluation Completion Rates

\begin{tabular}{lc}
\hline \multicolumn{2}{l}{ Evaluation Completion Rates $(\mathbf{n}=\mathbf{2 8 9})$} \\
\hline Job Skills & Completion Rates \\
Healthy Start & $212(73.34 \%)$ \\
Ready for 21 & $244(84.43 \%)$ \\
Safe Places & $270(93.43 \%)$ \\
\hline
\end{tabular}

The effectiveness of the BCS Youth Summit was captured by the VAS. The majority of summit participants reported learning "a lot" during the sessions (65.7\%) (See Table 3). The Safe Places session (83.2\%) had the highest ratings, followed by Ready for $21(68.7 \%)$, Healthy Start (66.7\%), and Job Skills (43.6\%). A majority of students also enjoyed the sessions (59.3\%). The Safe Places session had the highest rating (74.8\%), and the Job Skills session (33.2\%) had the lowest rating. Overall, a positive association was determined to exist between the participants perceptions of learning and enjoying (rho $=0.685, p<.001)$, although variations of these relationships were seen between sessions (see Table 4).

\section{Table 3}

Reported Learning and Enjoyment Levels by Youth Summit Participants

\begin{tabular}{|c|c|c|c|c|c|c|c|}
\hline \multicolumn{8}{|c|}{ Session-Specific Frequencies } \\
\hline \multicolumn{8}{|c|}{ I learned during this session. } \\
\hline & Job Skills & Healthy Start & Ready for 21 & Safe Places & Total & $x^{2}$ & $\mathbf{P}$ \\
\hline A Lot & $88(43.6 \%)$ & $152(66.7 \%)$ & $173(68.7 \%)$ & $168(83.2 \%)$ & $581(65.7 \%)$ & 90.938 & 0.000 \\
\hline Some & $84(41.6 \%)$ & $57(25.0 \%)$ & $74(29.4 \%)$ & $32(15.8 \%)$ & $247(27.9 \%)$ & & \\
\hline Not A Lot & $30(14.9 \%)$ & $19(8.3 \%)$ & $5(7.0 \%)$ & $2(1.0 \%)$ & $56(6.3 \%)$ & & \\
\hline \multicolumn{8}{|c|}{ I enjoyed this session. } \\
\hline & Job Skills & Healthy Start & Ready for 21 & Safe Places & Total & $x^{2}$ & $\mathbf{P}$ \\
\hline A Lot & $67(33.2 \%)$ & $145(63.6 \%)$ & $161(63.9 \%)$ & $151(74.8 \%)$ & $524(59.3 \%)$ & 110.898 & 0.000 \\
\hline Some & $91(45.0 \%)$ & $61(26.8 \%)$ & $83(32.9 \%)$ & $48(23.8 \%)$ & $283(32.0 \%)$ & & \\
\hline Not A Lot & $44(21.8 \%)$ & $22(9.6 \%)$ & $8(3.2 \%)$ & $3(1.4 \%)$ & $77(8.7 \%)$ & & \\
\hline
\end{tabular}

Table 4

Correlations between Learning and Enjoyment among Youth Summit Participants

\begin{tabular}{|c|c|c|}
\hline \multicolumn{3}{|c|}{ Correlations: Learned \& Enjoyed } \\
\hline & Correlation & $\mathrm{n}$ \\
\hline Job Skills & $0.680^{\star \star}$ & 202 \\
\hline Healthy Start & $0.750^{\text {** }}$ & 228 \\
\hline Ready for 21 & $0.568^{\star *}$ & 252 \\
\hline Safe Places & $0.595^{* *}$ & 202 \\
\hline Overall & $0.685^{\star *}$ & 884 \\
\hline$\overline{* \star} \mathrm{p}<.001$ & & \\
\hline
\end{tabular}


Evaluator observations of youth during sessions were also performed by evaluation volunteers. Participants were observed generally enjoying the sessions and were engaged throughout many of the sessions. Although all Youth Summit sessions were developed to be interactive and incorporated many experiential activities relevant to real world experiences, the Ready for 21 and Safe Places sessions were observed to be more engaging. As a strategy to actively engage participants, the Safe Places sessions included a close up examination of internet safety for social media sites such as Facebook. Session presenters provided an array of heuristic examples of fictitious Facebook pages that allowed the participants to discuss problems with each page and reflect about how displaying different types of information can result in varying levels of safety threats.

The use of behavioral observations enabled the Youth Summit Evaluation Team to effectively triangulate the accuracy of the VAS to measure outcomes associated with the BCS Youth Summit's effectiveness. The behavioral observation reporting was consistent with the selfreported VAS data results (findings of behavioral observations reported elsewhere).

\section{Discussion and Conclusion}

\section{Summary}

The results of this study are consistent with prior research revealing the benefits of youth being engaged in leadership development opportunities. This is consistent with the scholarship of experiential learning which stresses that the ideal learner is actively engaged in a quality learning process (Dewey, 1938; Kolb, 1984; Smith, 1991). The use of interactive summit sessions was viewed as engaging and led many students to view the opportunities available to them more positively. This further confirms what Mezirow (1997) described as transformative learning which encouraged youth in this study to change their frame of reference by reflecting on more positive attitudes.

One especially successful aspect of the Youth Summit planning was seen in the Ready for 21 sessions. This session was created by the event planners in response to a pre-administered survey of youth inquiring about their career aspirations. Then, caring adult volunteers representing the various professional careers identified by the students lead sessions to educate about aspects of their employment. This pre-Summit planning and youth involvement is vital during program development because it allows the youth to view their voice as important. Further, it allows for meaningful interaction between youth and adult role models. Positive youth-adult relationships are the center of positive youth development, in as such; young people must feel a strong connection with adults and their community.

The summit provided a supportive environment for the youth to explore the Five Promises. The sessions and activities reinforced the Five Promises and provided each youth with a sense of enjoyment and learning opportunity. Other aspects of the Summit, such as the youth seeing their suggestions for topics and professional careers adopted, further enhanced their experience and enhanced the level of youth voice in the event and planning process. The combination of engagement and voice produced lifelong learning skills that will enhance their transition to adulthood.

\section{Limitations}

The primary limitation of this evaluation methodology is the reliability of the VAS measure. The VAS was limited due to including only 2 items. Each item was developed to capture participants' 
perceptions based on independent concepts. Therefore, reporting the scale's reliability (Cronbach's a $=0.83$ ) may be inappropriate. However, the internal validity of the VAS (i.e., determining if the VAS accurately measured what the evaluators intended it to measure) was provided (see McKyer, Outley, \& Smith, 2009 for detailed methodology) and shown to be effective.

\section{Recommendations}

Based on the study findings the following recommendations are offered:

(1) Given the effectiveness of this program to reach a large number of youth with positive outcomes, it is recommended to use this large-event structure, evaluation methods, and evaluation tools in other settings (i.e., schools and out-of-school time settings), age groups (i.e., elementary and high school aged), and topics (e.g., drug use, sexual health, safety specific events).

(2) Encourage the utilization of experiential activities that can engage participants regardless of the session topic to enhance effectiveness.

(3) Assemble a diverse planning committee to ensure all aspects are covered and community assets/resources are effectively utilized.

(4) Engage participants from the beginning to ensure they are valued and the topics they would like to discuss/learn about are included (and sessions are hosted in context that is relevant to the youth participants).

(5) If resources are available, incorporate more advanced/rigorous evaluation techniques (i.e., pre/post evaluations to complement VAS and observations) and/or include a process evaluation for use with the summit volunteers).

(6) Host a pre-Summit evaluation training to properly collect data and make use of the measurement tools.

\section{References}

America's Promise Alliance (1997). Available online at: http://www.americaspromise.org.

Breitbart, M.M., \& Kepes, I. (2007). The YouthPower story: How adults can better support young people's sustained participation in community-based planning. Children, Youth and Environments, 1入2), 226-253.

Cahill, C. (2007). Doing research with young people: Participatory research and the rituals of collective work. Children's Geographies, 5(3), 297-312.

Cahill, C. \& Hart, R.A. (2007). Re-thinking the boundaries of civic participation by children and youth in North America. Children, Youth and Environments 17, (2): 213-225.

Chambers C.T., \& Craig K.D. (1998). An intrusive impact of anchors in children's faces pain scales. Pain, 78, 27-37.

Checkoway, B., Dobbie, D., \& Richards-Schuster, K. (2003). Involving young people in community evaluation research. Community Youth Development Journal, 4, 7-11. 
Checkoway, B., \& Richards-Schuster, K. (2004). Youth participation in evaluation and research as a way of lifting new voices. Children, Youth and Environments, 14(2), 84-98.

Checkoway, B., \& Richards-Schuster, K. (2003). Youth participation in community evaluation research. American Journal of Evaluation, 24, 21-33.

Dworkin, J.B., Larson, R., \& Hansen, D. (2003). Adolescents' accounts of growth experiences in youth activities. Journal of Youth and Adolescence, 32, 17-26.

Ginwright, S., Noguera, P., \& Cammarota, J. (eds.) (2006). Beyond resistance! youth activism and community change: New democratic possibilities for practice and policy for America's youth. New York: Routledge.

Goodyear, L. \& Checkoway, B. (2003). Establishing the importance of youth participation in community evaluation research. Community Youth Development Journal, 4, 5.

Lerner, R.M. (2003). Developmental assets and asset-building communities: A view of the issues. In R.M. Lerner \& P.L. Benson (Eds.). Developmental assets and asset-building communities: Implications for research, policy, and practice (pp. 3-18). New York: Kluwer.

McKyer, E. L., Outley, C., \& Smith, M. L. (2009). Pragmatic evaluation of large events with youth: Use of a brief visual analog scale measure. American Journal of Health Studies, 24(4), 423-429.

Perkins, D.F., Borden, L.M., Keith, J.G., Hoppe-Rooney, T., \& Villarruel, F.A. (2003). Community youth development: A partnership for creating a positive world. In F.A. Villarruel, D.F. Perkins, L.M. Borden, \& J.G. Keith (Eds.), Community youth development: Practice, policy, and research (1-23). Thousand Oaks, CA: Sage.

Perkins, D.F., \& Borden, L.M. (2003). Key elements of community youth development. In Villarruel, F. A., Perkins, D. F., Borden, L. M., \& Keith, J. G. (Eds.), Community Youth Development: Programs, policies, and practices (pp. 327-340). Thousand Oaks, CA: Sage Publications.

Proescholdbell, S.K., Scott, S.A., \& Placona, M.L. (2005). Above and beyond "it was great": Evaluation of youth summits using innovative methods. National Conference on Tobacco or Health. Chicago, IL.

Smith, T., Genry, L., \& Ketring, S. (2005). Evaluating a youth leadership life skills development program. Journal of Extension, 43(2). Available at: http://www.joe.org/joe/2005april/rb3.shtml.

(C) Copyright of Journal of Youth Development $\sim$ Bridging Research and Practice. Content may not be copied or emailed to multiple sites or posted to a listserv without copyright holder's express written permission. However, users may print, download or email articles for individual use. 